\title{
Anticoagulation with Warfarin: Roles of Adherence, Social Support and Illness Perception
}

Saiful Nizam MV Mohamed Koya

Department of Specialist Pharmacy, Jerantut Hospital, Malaysia

\begin{abstract}
Objectives: This study was aimed to determine (1) the associations between adherence to warfarin, social support, perception of illness, and demographic factors on the quality of international normalized ratios (INRs); as well as (2) the relationship between the patients' scores in the Malaysian medication adherence scale (MALMAS) and their current INRs.

Method: This cross-sectional survey was conducted from November 2017 to January 2018 at the warfarin clinic of Jerantut Hospital, Malaysia.

Results: Some 58 participants were recruited, of whom 70.7\% were diagnosed with atrial fibrillation (AF). Overall, 87.9\% of the participants claimed adherence to their warfarin regimens. Patients with good-quality INR therapy were significantly older, had a higher median income and longer appointment durations. In terms of illness perception (IP), participants with good-quality INR therapy had significantly lower scores in the identity, personal control, and consequence domains. Overall, the total scores for IP were significantly lower in the good-quality INR therapy. Meanwhile, the MALMAS scores were significantly lower in patients with subtherapeutic current INR. However, there were no associations between warfarin adherence and perceived social support with current TTR.

Conclusion: Monitoring of demographic factors and IP's domains is vital since they were associated with quality of INR therapy. Meanwhile, the occurrence of sub-therapeutic current INR should raise suspicion of poor adherence in these patients. Overall, IP and MALMAS are useful tools that should be integrated into the patient care protocols.
\end{abstract}

Keywords: Warfarin, adherence, illness perception, social support, time in therapeutic range

\section{INTRODUCTION}

Today, pharmacists have become actively involved in patient monitoring and warfarin-prescribing [1]. Warfarin is used in the treatment of various thromboembolism-related disorders [2] but owing to its narrow therapeutic index, regular international normalized ratio (INR) monitoring is required. This is vital for (1) patients' safety in term of preventing complications like minorto-severe bleeding in light of over-anticoagulation [2], and (2) ensuring treatment efficacy by avoiding sub-therapeutic INR due to insufficient dosing[2].

In the current settings, physicians and pharmacists usually prescribe clinical follow-ups ranging from three days (in unstable patients) to three months (in stable patients) and dose adjustments are made based on a normogram provided by the Malaysian Ministry of Health [3].

The duration of warfarin treatment ranges from a few months to lifelong [2] and healthcare practitioners are aware that the achievement of prolonged time in therapeutic range (TTR) is a key objective of the treatment [2]. Hence, a good motivation and long-term commitment from both patients and caregivers in terms of adherence to follow-ups and lifestyle changes such as diet restriction as well as warfarin intake is needed [4].

Corresponding author: Saiful Nizam M V Mohamed Koya Department of Specialist Pharmacy, Jerantut Hospital 27000, Pahang, Malaysia

Email: saiful.nizam@moh.gov.my; Phone: +6092663333
While the associations between social support and TTR have rarely been explored, yet variations in relationships between warfarin adherence $(4,5,15)$ and illness-perception (IP) $(6,26)$ with TTR have been reported in different studies making their findings difficult to be generalized for clinical practices. Thus in current study, we aimed to determine the relationships between adherence to warfarin with TTR and current international normalized ratio (INR) and also the relationships between social support and IP on TTR.

\section{METHOD}

This cross-sectional survey was conducted at the warfarin clinic of Jerantut Hospital, Malaysia from November to December 2017. It was approved by the Medical Research and Ethics Committee (MREC) (registration number: NMRR-17-203637528). Convenience sampling was performed, and written consent was obtained from the potential respondents prior to the survey. Participants who were at least 18 years of age, able to give consent, and on warfarin for at least six months were recruited. Those who refused to participate, or had language barriers, speech/ hearing disabilities, mental disorders, and histories of defaulting treatment were excluded. The researchers spent between 20 and 30 minutes to conduct the survey on each patient during warfarin clinic days.

In the pilot study, the Malay-version Malaysian Medication Adherence Scale (MALMAS) [7] scores of 30 adherent (TTR > $60 \%$ ) and non-adherent (TTR $<60 \%$ ) patients were normally distributed with a standard deviation of 0.8. Meanwhile, the true difference between both groups' means was 0.5 . With 
reference to this, 41 subjects were needed for the adherent and non-adherent groups respectively to achieve a study power of $80 \%$. Also, the Type I error in this test was set at 0.05 .

MALMAS [7], Multidimensional Scale of Perceived Social Support (MSPSS-M) [8], and illness perception (IP) [9] questionnaires were used to assess warfarin adherence, social support, and IP respectively. Demographic data was obtained verbally from the patients, while six-to-twelve-month INR histories were extracted from participants' INR booklets.

MALMAS consisted of eight questions. The first item of the MALMAS contained five possible responses: (1) all the time, (2) often, (3) sometimes, (4) rarely, and (5) never. The remaining seven items had dichotomous yes-no responses options. Items two to four and six to eight were reverse coded (i.e. "no" = 1 , "yes" = 0), while the converse was true for item five ("no" = 0 , "yes" =1). The first item had five negatively scored response options that ranged from zero (all the time) to one (never). The total MALMAS score, which ranged from 0 to 8 , was used to assess the patients' medication adherence one month prior to the administration of the questionnaire [7]. Patients whose scores were less than six were categorized as non-adherent.

MSPSS-M comprised of 12 questions whose scores ranged from one to seven marks each. Hence, the total mark ranged from seven to 84 . Questions 1, 2, and 10 evaluated the patients' perceptions of support from their significant others, questions $3,4,8$, and 11 family members, and questions $6,7,9$, and 12 friends $[8,10]$. Higher score reflected better social support.

The Malay version of IP was validated on the hypertensive population in Malaysia, and the Cronbach's alpha was found to be 0.65 . This questionnaire consisted of eight questions, each of which was scored between zero and ten. Ergo, this questionnaire had a maximum total mark of 80 . The questions on personal control (question 3), treatment control (question 4), and understanding of illness (question 7) were reversescored, whereby lower scores indicated a less negative view of the illness. Conversely, higher overall scores indicated more negative view of the illness [9]. Time in therapeutic range (TTR) was measured using the Rosendaal formula [11, 12], whereby participants who had a TTR of $>60 \%$ were considered to have achieved good quality INR control $[13,14,29,30]$.

Statistical analyses were performed using the Statistical Package for Social Sciences (SPSS) version 18.0 software. Chisquare test was employed to analyze the categorical variables and T-test or Mann Whitney $U$ test was used to determine the relationships between the categorical and numerical variables. The outcomes of the continuous variables were expressed as means \pm standard deviations (SDs), or medians and interquartile ranges (IQRs) where applicable. A P-value of $<0.05$ was considered to be statistically significant.

\section{RESULTS}

Participants' characteristics

As of December 2017, 75 patients have attended the warfarin clinic at Jerantut Hospital, all of whom were approached to solicit their participation in the survey. However, nine were excluded owing to language barriers, six on treatment for less than six months, and two with histories of defaulting treatment in the past year. The remaining 58 patients agreed to participate in the survey, hence giving a power of $65 \%$.

In the current survey, $48.3 \%(n=28)$ of the participants were males, and the median age was 63.5 years (IQR: 16.3). The majority of the respondents $(70.7 \% ; n=41)$ were diagnosed with atrial fibrillation (AF) and received warfarin for a median of 41.5 months (IQR: 80.0). For the past six to 12 months, the median follow-up interval was once every 27 days (IQR: 19) and the mean warfarin daily dose of $2.5 \pm 1.2 \mathrm{mg}$ per day.

Overall, $87.9 \%(n=51)$ of the participants claimed adherence to their warfarin regimens. For IP, participants scored the highest in the timeline- (median: 9; IQR: 4.3) and illness-specific (median: 9; IQR: 2) domains. Overall, mean total IP score was $35.1 \pm 8.1$. As for social support, the median scores for spousaland friend-support were both 20 (IQR: 9 and 5 respectively). The mean scores for family support and total social support were $23.7 \pm 3.6$ and $65.3 \pm 11.3$ respectively. These data are presented in Table 1.

\section{Characteristic differences between patients with good and poor quality INR control}

In terms of demographic factors, it was noted that patients with good quality INR control were older (median age: 68 years; IQR: 18 ) than their poor quality INR control counterparts (median age: 50 years; IQR: 22$)(P=0.013)$. The former group also recorded a higher median income (Malaysian Ringgit/ MYR 1 000; IQR: 1300) vis-a-vis the latter group (MYR 300; IQR: 1310). Patients with good INR control were under longer follow-up intervals (median: 42 days; (IQR: 20) than poor quality INR controlones (median: 24 days; IQR: 6) $(P=0.001)$. However, duration on warfarin treatment and daily warfarin dose had no significant association with INR control. Good INR control group had lower scores in the following domains: identity (median: 3.0 vs 4.5 ; IQR: 5.5 vs $4.0 ; \mathrm{P}=0.039$ ), personal control (median: 2.0 vs 3.0 ; IQR: 2.0 vs $2.0 ; P=0.047$ ), consequences (median: 1.5 vs $3.0 ;$ IQR: 3.0 vs $4.8 ; P=0.016$ ). Likewise, the total IP score was significantly lower in patients with good INR control (median: 32.1; IQR: 7.5) as compared to those with poor INR control (median: 37.5; IQR: 8.0) $(P=0.012)$. Other IP and perceived social support domains did not have a significant influence on INR control (Table 2).

\section{Relationship between MALMAS and current INR readings}

As shown in Figure 1, patients who managed to maintain the target INR for the past four to six weeks had significantly higher MALMAS scores (median: 8.0; IQR: 1.0) than their counterparts who failed to do so (median: 7.0; IQR: 2.0) $(P=0.022)$. 


\section{DISCUSSION}

In addition to the relationship between MALMAS scores and current INR readings, this was the first study that investigated the associations between medication adherence, social support, and illness perception with INR control.

\section{Roles of TTR}

TTR lower than $60 \%$ increased risks of bleeding $[12,13]$ yet its associations with stroke and systemic embolism varied between different studies[12,13,14]. A study between subgroups of patients with TTRs of 60 to $75 \%$ versus those that exceeded $75 \%$ found that the risks of major bleeding, mortality, and stroke were not significantly different between the two groups [14]. Thus the choice of using the TTR value of $60 \%$ and above as an indication of good quality INR therapy $[29,30]$.

\section{Associations between demographic factors and warfarin therapy on TTR}

Our findings supported the associations between advanced age and higher income on quality of INR therapy $[17,18]$. The importance of good quality INR therapy in lower-income patients should not be underestimated since the failure to achieve the same will ultimately results in higher risks of haemorrhage and death [19].

Predictably, those with poor quality INR control had significantly shorter follow-up intervals (i.e. time between follow-up sessions) as compared to patients with good quality INR control. In this study, patients who achieved good quality INR had their appointments once every 42 days, which was much longer than that of their overseas counterparts (21-24 days) [20]. On the contrary, patients with lower TTRs had their appointments scheduled more frequently, i.e. once in every three weeks or so. Hence, this could be an indication that shorter follow-up intervals should be considered in patients with poor quality INR in current setting.

\section{Adherence}

Multiple tools have been used to determine warfarin adherence such as pill counts, medication event monitoring systems (MEMS), and self-reported questionnaires $[4,5,12,15,21,22]$. Nonetheless, self-reported adherences varied between studies depending on the assessment tools used $[4,5,12,15,22]$. A frequently-utilized questionnaire for the evaluation of medication adherence is the eight-item modified Morisky medication adherence scale (MMAS-8) [4,5,12]. From there, a new questionnaire has been developed by Malaysian researchers, and it was named "Malaysian medication adherence scale" (MALMAS) [7].

\section{Adherence and TTR}

Despite the high adherence to warfarin (about $88 \%$ ) in this study, only around $45 \%$ of the patients achieved good quality INR control. Nonetheless, this figure was still slightly higher than the $15 \%$ to $35 \%$ in other studies $[4,5]$. It should be noted that comparisons are difficult since those studies have used higher cut-off points of $70 \%$ and $75 \%$ for defining therapeutic TTR [4,5]. Also, lack of clear correlation between self-reported adherence and TTR is not uncommon probably due to different TTR calculations and therapeutic TTR definitions $[4,5,15]$.

Even though a recent study has reported that warfarin adherence was related to TTR [5] yet other research have found that only $26 \%$ to $35 \%$ of patients managed to achieve a TTR of more than $75 \%$ despite the presence of self-reported adherence levels of up to $46 \%$ to $48 \%[4,15]$. Nevertheless, this observation was not unexpected owing to the fact that MMAS8 had limited recall period of two weeks only [4]. This was supported by our finding that higher MALMAS scores were only predictive of current INR readings but not TTR. Likewise, previous studies have shown that adherence measurement tools like the visual analogue scale (VAS) and 7-day recall test were more predictive of short-term INR changes [22].Other tool such as MEMS have revealed that good adherence within the past 12 months was associated with good TTR [23] yet this device is far too costly to be routinely used in daily clinical practice [21]. Based on this finding, monitoring of adherence should essentially comprised the administration of selfreported questionnaires such as MALMAS at every visit, along with an emphasis on warfarin adherence in patients with poor quality INR control.

\section{Social support and TTR}

In hypertensive patients, medication-adherence counselling and treatment optimization by pharmacists have led to improvements in social support and blood pressure. Nevertheless, the effect of social support on blood pressure was insignificant [24].

Based on a previous study [24], it was expected that social support did not markedly differ between the poor and good quality INR control groups. This was due to the fact that the participants of this research were managed (in terms of warfarin dosing, warfarin adherence, and lifestyle modification counselling) by trained pharmacists at every visit. This indicates that one of the most important outcomes of social support is to retain patients within the care system and hence, avoid complications that are attributable to their illnesses [25].

\section{IP and TTR}

IP has been explored in warfarin-taking patients prior to switching treatment to novel oral anticoagulants (NOACs) [6] as well as its changes upon receiving educational interventions [26].

It was reported that IP did not predict TTR changes among 46 and 51 participants whom underwent educational interventions and the usual care respectively [26]. However, this could be attributed to the fact that IP was only assessed in 27 participants. On the contrary, a study on 148 AF or venous thromboembolism (VTE) has found that the scores for the consequence and timeline (cyclical) domains were significantly 
higher in patients whose TTRs were less than $50 \%$ as compared to those whose TTRs exceeded 75\% [6]. Meanwhile timeline (acute chronic) and illness coherence domains scores were significantly lower in the former group relative to the latter group [6]. Evidently, the only similarity between this research and the aforementioned one [6] was the significantly higher consequence domain scores in patients with good quality INR control vis-à-vis those with poor quality INR control. Apart from that, patients with shorter TTRs had higher scores in the identity domain, thereby denoting a more negative effect of the illness on their lives.

IP interacts with several factors like adherence to medications and lifestyle modifications. For instance, improved treatment control had a positive impact on medication adherence in hypertensive patients [27]. Apparently, good medication adherence in diabetic patients has resulted in better outcomes and personal control scores than their poorly compliant counterparts [28]. In this study, it was likely that the long-term maintenance of self-management in terms of diet control [16] and medication adherence [21] has helped the participants to achieve good quality INR control, which in turn produced better outcomes and personal control scores.

With the assumption that IP was a better indicator of long-term anticoagulation control (based on the poorer IP in patients with lower TTRs), IP-related interventions should be held during patients' encounters. Since educational interventions might not improve the IP [26], different approaches - like exploring issues and providing solutions from the IP's point of view - might be better mechanisms for patients to adapt to their illnesses [28].

\section{Strength and limitations}

This was the first study that investigated the relationships between TTR and INR with the newly developed MALMAS questionnaire in patients prescribed with warfarin. Current finding has also provided preliminary evidence that current INR readings was associated with MALMAS scores. However, this study was not without limitations. The sample size was rather small and inadequately powered due to the small numbers of patients diagnosed with heart-related conditions within this locality that required them to receive warfarin treatment.

\section{CONCLUSION}

To improve the quality of INR therapy in patients receiving warfarin, a multifaceted approach which addresses essential factors like medication adherence, social support, and patients' perceived severity of their illnesses has to be implemented. Ideally, warfarin adherence assessments should be performed during every follow-up session, along with periodical evaluations of illness perceptions.

Conflicts of interest: Author declares no conflicts of interest. Disclosure of grants/funding: This study did not receive any grant or funding.

\section{References}

1. Hasan SS, Shamala R,Syed IA, Basariah N, Chong DWK, Mei TK et al., 2011. Factors affecting warfarin related knowledge and INR control of patients attending physicians and pharmacists' managed anticoagulation clinics. J Pharm Pract. 24,485-493.

2. Horton JD, Bushwick BM.,1999. Warfarin therapy: Evolving Strategies in Anticoagulation. Am Fam Physician. 59, 635-636.

3. Pharmaceutical Services Division (2010) Protocol of Medication Therapy Adherence Clinic (MTAC): Warfarin. Retrieved from http://www.pharmacy.gov.my/v2/en/documents/pro tocol-medication-therapy-adherence-clinic-mtacwarfarin.html

4. Mayet AY, 2016. Patient adherence to warfarin therapy and its impact on anticoagulation control. Saudi Pharm J. 24,29-34.

5. Ababneh MA, AL-Azzam SI, Alzoubbi KH, Rababa'h $A M, 2016$. Adherence in outpatients taking warfarin and its effect on anticoagulation control in Jordan. Int J Clin Pharm. 38,816-821.

6. Abdou JK, Patel JP, Vadher B, Brown A, Roberts LN, Patel RK et al., 2015. Patients Prescribed Warfarin with Poor Time in Therapeutic Range (TTR) Have Different Beliefs about Their Illness and Anticoagulation Therapy Compared to Those with a Good TTR-Early Results from the Switching Study.

7. Chung WW, Chua SS, Lai PSM, Morisky DE, 2015. The Malaysia Medication Adherence Scale (MALMAS): Concurrent Validity Using a Clinical Measure among People with Type 2 Diabetes in Malaysia. PLoS One. 10, e0124275.

8. Ng CG, Siddiq ANA, Aida SA, Zainal NZ, Koh OH, 2018. Validation of the Malay version of the Multidimensional Scale of Perceived Social Support (MSPSS-M) among a group of medical students in Faculty of Medicine. Asian Journal of Psychiatry. 3,36.

9. Norfazilah A, Samuel A, Law PT, Ainaa A, Syahnaz MH, Azmawati MN, 2013. Illness perception among hypertensive patients in primary care centre UKMMC. Malaysian Fam Physician. 8, 19-25.

10. Zimet GD, Dahlem NW, Zimet SG, Farley GK,1988. The multidimensional scale of perceived social support. J of Personality Assessment. 52, 30-41.

11. Rosendaal FR, Cannegieter SC, van der Meer, Briet E, 1993. A method to determine the optimal intensity of oral anticoagulant therapy. Thromb haemost. 69, 236-239.

12. Pokorney SD, Simon DN, Thomas L, Fonarow GC, Kowey PR, Chang P et al..2015. Patients' time in therapeutic range on warfarin among US patients with atrial fibrillation: Results from ORBIT-AF registry. Am Heart J. 170,141-148. 
13. Vestergaard, AS, Skjøth F, Larsen TB, Ehlers LH, 2017. The importance of mean time in therapeutic range for complication rates in warfarin therapy of patients with atrial fibrillation: A systematic review and metaregression analysis. PloS one. 12(11), e0188482.

14. White HD, Gruber M, Feyzi J, Kaatz S, Tse HF, Husted S et al., 2007. Comparison of outcomes among patients randomized to warfarin therapy according to anticoagulant control: results from SPORTIF III and V. Archives of internal medicine. 167(3), 239-245.

15. Radaideh KM, Matalqah LM, 2017 Factors Associated with adherence to Warfarin among atrial Fibrillation Patients and its Impact on Anticoagulation Control. Int J Cardiovasc Res. 6,3.

16. Ciurus T, Cichocka-Radwan A, Lelonek M, 2015. Factors affecting the quality of anticoagulation with warfarin: experience of one cardiac centre. Polish journal of cardio-thoracic surgery. 12(4), 334.

17. Macedo AF, Bell J, McCarron C, Conroy R, Richardson J, Scowcroft A, et al,.2015. Determinants of oral anticoagulation control in new warfarin patients: analysis using data from Clinical Practice Research Datalink. Thrombosis research. 136(2), 250-260.

18. Dlott JS, George RA, Huang X, Odeh M, Kaufman HW, Ansell J, et al,.2014. A national assessment of warfarin anticoagulation therapy for stroke prevention in atrial fibrillation. Circulation, CIRCULATIONAHA-113.

19. Cressman AM, Macdonald EM, Yao Z, Austin PC, Gomes T, Paterson JM et al., Canadian Drug Safety and Effectiveness Research Network (CDSERN. (2015). Socioeconomic status and risk of hemorrhage during warfarin therapy for atrial fibrillation: A populationbased study. American heart journal. 170(1), 133-140.

20. Dimatteo MR, 2004. Social support and patient adherence to medical treatment: A Meta-Analysis. Health Psychology. 23, 207-218.

21. Lam WY, Fresco P, 2015. Medication adherence measures: an overview. Biomed. Res. Int. 2015, 217047.
22. Cazes JS, Finkleman BS, Chen J, Brensinger CM, Epstein AE, Streiff MB et al.,2017. Association between patient-reported medication adherence and anticoagulation control. The American Journal of Medicine. 130, 1092-1098.

23. Parker CS, Chen Z, Price M, Gross R, Metlay JP, Christie JD et al.,2007. Adherence to warfarin assessed by electronic pill caps, clinician assessment, and patient reports: results from the IN-RANGE study. J Gen Intern Med. 22, 1254-1259.

24. Criswell TJ, Weber CA, Xu Y, Carter BL, 2010. Effect of self-efficacy and social support on adherence to antihypertensive drugs. Pharmacotherapy: The Journal of Human Pharmacology and Drug Therapy. 30(5), 432-441.

25. Seliverstov I, 2011. Practical management approaches to anticoagulation non-compliance, health literacy, and limited English proficiency in the outpatient clinic setting. Journal of thrombosis and thrombolysis.31 (3), 321-325.

26. Clarkesmith DE, Pattison HM, Lip GYH, Lane DA, 2013. Educational intervention improves anticoagulation control in atrial fibrillation patients: The TREAT Randomised Trial. PLoS One. 8, e74037.

27. Chen SL, Tsai JC, Lee WL, 2009. The impact of illness perception on adherence to therapeutic regimens of patients with hypertension in Taiwan. J Clin Nurs. 18:2234-2244.

28. Broadbent E, Donkin L, Stroh JC, 2011. Illness and treatment perceptions are associated with adherence to medications, diet and exercise in diabetic patients. Diabetes Care. 34, 338-340.

29. Bernaitis, N. , Badrick, T. , Davey, A. K. and Anoopkumar-Dukie, S, 2016. Quality of warfarin control in atrial fibrillation patients in South East Queensland, Australia. Intern Med J, 46: 925-931.

30. Caldeira, D., Cruz, I., Morgado, G., Stuart, B., Gomes, C., Martins, C, et al. 2014. Evaluation of time in therapeutic range in anticoagulated patients: a singlecenter, retrospective, observational study. BMC research notes, 7,891 . 


\section{Table 1. Participants' characteristics}

\begin{tabular}{|c|c|}
\hline Characteristics & Population ( $\mathrm{N}=58)$ \\
\hline Age (years) & $63.5(16.3)$ \\
\hline Male gender $(n, \%)$ & $28(48.3)$ \\
\hline Income (RM) & $950(1950)$ \\
\hline \multicolumn{2}{|l|}{ Diagnosis (n,\%) } \\
\hline $\mathrm{AF}$ & $41(70.7)$ \\
\hline Others & $17(29.3)$ \\
\hline Duration on warfarin treatment (months) & $41.5(80.0)$ \\
\hline Appointment length (days) & 27(19) \\
\hline Daily dose $(\mathrm{mg})^{\mathrm{a}}$ & $2.5(1.2)$ \\
\hline \multicolumn{2}{|l|}{ TTR control } \\
\hline$>60 \%$ & $26(44.8)$ \\
\hline$<60 \%$ & $32(55.2)$ \\
\hline \multicolumn{2}{|l|}{ Adherence (n,\%) } \\
\hline Adherent & $51(87.9)$ \\
\hline Nonadherent & $7(12.1)$ \\
\hline \multicolumn{2}{|l|}{ Illness perception } \\
\hline Identity & $3.5(5.3)$ \\
\hline Timeline & $9.0(4.3)$ \\
\hline Personal control & $3.0(1.0)$ \\
\hline Treatment control & $2.5(2.0)$ \\
\hline Consequence & $3.0(4.0)$ \\
\hline Illness concern & $9.0(2.0)$ \\
\hline Illness coherence & $3.0(3.0)$ \\
\hline Emotional response & $4.0(5.3)$ \\
\hline Total illness perception score ${ }^{a}$ & $35.1(8.1)$ \\
\hline \multicolumn{2}{|l|}{ Social support } \\
\hline Spousal & 20.0(9.0) \\
\hline Family $^{a}$ & $23.7(3.6)$ \\
\hline Friends & $20.0(5.0)$ \\
\hline Total social support ${ }^{\mathrm{a}}$ & $65.3(11.3)$ \\
\hline
\end{tabular}


Table 2. Factors influencing TTR

\begin{tabular}{|c|c|c|c|}
\hline & TTR $>60 \%$ & TTR $<60 \%$ & $P$ \\
\hline Age (years) & $68(18)$ & $59(22)$ & 0.013 \\
\hline Income (RM) & $1000(1300)$ & $300(1310)$ & 0.020 \\
\hline $\begin{array}{l}\text { Duration on warfarin } \\
\text { treatment (months) }\end{array}$ & 68(105) & $38(48)$ & 0.149 \\
\hline $\begin{array}{l}\text { Appointment length } \\
\text { (days) }\end{array}$ & $42(20)$ & $24(6)$ & 0.000 \\
\hline Daily dose $(\mathrm{mg})^{\mathrm{a}}$ & $2.3(1.0)$ & $2.7(1.2)$ & 0.170 \\
\hline \multicolumn{4}{|l|}{ Illness perception } \\
\hline Identity & $3.0(5.5)$ & $4.5(4.0)$ & 0.039 \\
\hline Timeline & $9.0(5.0)$ & $9.0(2.8)$ & 0.489 \\
\hline Personal control & $2.0(2.0)$ & $3.0(2.0)$ & 0.047 \\
\hline Treatment control & $2.5(2.0)$ & $2.5(1.0)$ & 0.406 \\
\hline Consequence & $1.5(3.0)$ & $3.0(4.8)$ & 0.016 \\
\hline Illness concern & $9.0(2.0)$ & $8.0(1.8)$ & 0.204 \\
\hline Illness coherence & $3.5(3.0)$ & $2.5(3.0)$ & 0.441 \\
\hline Emotional response & $3.0(6.0)$ & $5.5(5.0)$ & 0.106 \\
\hline Total illness score ${ }^{a}$ & $32.1(7.5)$ & $37.5(8.0)$ & 0.012 \\
\hline \multicolumn{4}{|l|}{ Social support } \\
\hline Spousal & $21.0(9.0)$ & $20.0(10.5)$ & 0.893 \\
\hline Familya & $23.9(4.0)$ & $23.5(3.1)$ & 0.628 \\
\hline Friends & $20.5(7.3)$ & $20.0(4.3)$ & 0.682 \\
\hline Total social support ${ }^{\mathrm{a}}$ & $65.6(12.2)$ & $65.0(10.6)$ & 0.828 \\
\hline Adherence $(n, \%)^{b}$ & & & 0.116 \\
\hline Adherent & $25(96.2)$ & $26(81.3)$ & \\
\hline Non-adherent & $1(3.8)$ & $6(18.7)$ & \\
\hline
\end{tabular}

Data are shown as median (IQR) except where indicated

aData are shown as mean (SD)

${ }^{\text {b}}$ Data reported using Fisher's Exact test 